\title{
Cholesterol synthesis and high density lipoprotein uptake are regulated independently in rat small intestinal epithelium
}

\author{
C Lutton, G Champarnaud
}

\begin{abstract}
The rates of high density lipoprotein HDL uptake and cholesterol synthesis were compared in the normocholesterolaemic (SW) and genetically hypercholesterolaemic (RICO) rat intestine. The RICO rat has a hyperintestinal cholesterol synthesis. ${ }^{14} \mathrm{C}$ sucrose, a marker which becomes irreversibly entrapped within the cells, was used to measure total rat HDL uptake over 24 hours in the various cells of the small intestinal mucosa. The rates of sterol synthesis were estimated in vivo with $1-{ }^{14} \mathrm{C}$ acetate, as previously validated. The rates of HDL uptake in the upper villus cells were similar along the length of the small intestine in both types of rat, but the rates of sterol synthesis varied up to eightfold. When the mucosal epithelium was divided along the villus/crypt axis, HDL uptake increased two to threefold and cholesterol synthesis two to fivefold in the upper villus compared with the crypt cells in both SW and RICO rats. The high cholesterogenesis in the mucosal cells of the RICO rat is not related to a modified HDL cholesterol uptake. Thus, cholesterol synthesis and HDL uptake seem to be regulated independently in the rat small intestinal mucosa.
\end{abstract}

(Gut 1994; 35: 343-346)

The small intestine plays a key role in cholesterol balance. ${ }^{12}$ It is an active site for cholesterogenesis ${ }^{13}$ but in contrast to cholesterol absorption, which occurs predominantly in the upper villus cells of the proximal intestine, cholesterol synthesis take place predominantly in the duodenal and ileal crypts. ${ }^{45}$ In addition to its role in cholesterol absorption and synthesis, the intestine also seems to be an important site for the clearance of cholesterol from the plasma through low density lipoprotein (LDL) uptake. ${ }^{6}$ The rates of sterol synthesis and LDL uptake, however, seem to be independently regulated in the rat small intestinal epithelium. ${ }^{7}$ Specific high density lipoprotein (HDL) binding sites have also been shown in isolated rat intestinal mucosal cells. ${ }^{8}$ Since HDL uptake can also deliver cholesterol to intestinal cells, we question whether or not the rates of sterol synthesis and HDL uptake are coregulated. To answer this, we measured the in vivo rates of cholesterol synthesis and HDL cholesterol uptake in the mucosal cells along the length of the small intestine or on the villus in normocholesterolaemic or genetically hypercholesterolaemic (RICO) rats in which we have previously shown very high intestinal cholesterogenesis. ${ }^{9}$
Methods

ANIMALS

These studies were performed with male normocholesterolaemic (SW) and genetically hypercholesterolaemic (RICO) rats weighing mean (SD) 430 (20) $\mathrm{g}$ and provided by the CIBAGEIGY Breeding Unit. The animals were subjected to light cycling (light: $8 \mathrm{am}-8 \mathrm{pm}$ ) and were fed a semipurified laboratory chow containing $0.015 \%$ cholesterol. ${ }^{3}$ They were killed at 10 am without previous fasting. The mean (SD) concentrations of plasma HDL cholesterol $(1.095<\mathrm{d}<1.21)$ were $166.2(4.8) \mathrm{mg} / \mathrm{ml}$ and $196.9(8.2) \mathrm{mg} / \mathrm{ml}$ respectively in the SW and RICO rats.

\section{PREPARATION OF THE INTESTINAL EPITHELIAL} CELLS

Mucosal cells were isolated from the rat small intestine according to the method of Weiser ${ }^{10}$ as modified. ${ }^{3}$ This technique yielded cell fractions from different levels of the villus/crypt axis through incubation of four equal intestinal segments with EDTA containing phosphate buffer. The procedure had previously been validated by the ${ }^{3} \mathrm{H}$ thymidine procedure. ${ }^{3}$

DETERMINING HDL CLEARANCE IN THE INTESTINE HDL in a density range of $1.095-1 \cdot 21 \mathrm{~g} / \mathrm{ml}$ was isolated from the plasma of adult SW or RICO rats by preparative ultracentrifugation. ${ }^{11}$ This density range was chosen to minimise contamination by apolipoprotein (apo) E rich HDL. Under these conditions, labelling of the HDL protein moiety in the rat has already been shown to concern essentially apo AI. ${ }^{12}$ It always contains $<7 \%$ apo $\mathrm{E}$ and was not therefore purified further.

The HDL apolipoproteins (mostly apo AI) were labelled with ${ }^{14} \mathrm{C}$ sucrose as described by Pittman $e t a l^{13}$ with slight modifications. ${ }^{14}$ Each animal received a single pulse of $\left|{ }^{14} \mathrm{C}\right|$ sucrose HDL $\left(2-3 \cdot 10^{6} \mathrm{dpm}, 0 \cdot 2-0.3 \mathrm{mg}\right.$ of $\mathrm{HDL}$ protein) and plasma radioactivity was measured over 24 hours. The purity of labelled HDL was checked five and 24 hours after the single pulse. Virtually all radioactivity ( $>95 \%$ ) was recovered in the $\mathrm{HDL}$ fraction. Since ${ }^{14} \mathrm{C}$ sucrose lipoprotein is irreversably trapped in the cells, the HDL clearance rate $\left(\mathrm{CR}_{\mathrm{T}}\right)$ can be calculated by the method described by Day. ${ }^{15}$ If the $a_{p}(t)$ function represents the time course of plasma specitif activity and $q_{p}\left(t_{n}\right)$ the radioactivity in a tissue, the $C_{T}$ is obtained by the following equation: 


$$
C R_{T}=\frac{q_{p}\left(t_{n}\right)}{\int_{0}^{t_{n}} a_{p}(t) d t}
$$

Rat HDL cholesterol uptake (expressed as nmol HDL cholesterol. $\mathrm{h}^{-1} / \mathrm{mg}$ cell DNA) is calculated from the HDL plasma clearance and the HDL cholesterol concentration. Epithelial cell fractions were assayed for ${ }^{14} \mathrm{C}$ radioactivity after digestion in $1 \mathrm{ml}$ of soluene 350 , acidification with acetic acid, and counting in a Kontron scintillation spectrometer. Preliminary assays showed that aliquots of the tissue subjected to lipid extraction gave results similar to those of non-delipidated samples. ${ }^{14}$

\section{DETERMINING STEROL SYNTHESIS IN THE} INTESTINE

In vivo sterol synthesis was estimated in the various intestinal mucosal cells 70 minutes after a subcutaneous injection of $200 \mu \mathrm{Ci}(7 \cdot 4 \mathrm{MBq})$ $\left[1-{ }^{14} \mathrm{C}\right]$ acetate, as described previously. ${ }^{9}$ This method was found to give results similar to the technique using tritiated water $^{3}$ and has been previously described. ${ }^{16}$ Although different isotopic enrichments of acetyl-CoA used for cholesterol synthesis have been shown in the liver and intestine, we suggest that similar isotopic enrichment of acetyl-CoA occurs in the various enterocytes since the same results were obtained with ${ }^{14} \mathrm{C}$ acetate and tritiated water ${ }^{3}$ and no variations in the diluted acetyl-CoA can be observed in the intestinal mucosa in different physiological situations. ${ }^{17}$

\section{DATA ANALYSIS}

Results are expressed as mean (SEM). Comparisons between groups were made using the Student's $t$ test. Cholesterogenesis and HDL cholesterol uptake relationships were analysed by regression analysis and the Spearman rank correlation coefficient.

TABLE I Rates of high density lipoprotein (HDL) clearance (in nl plasma HDL. $h^{-1} / m g$ cellular DNA) in the small intestinal mucosa of SW and RICO rats. (The data are expressed as a percentage of the value obtained for crypt duodenal cells in SW rats

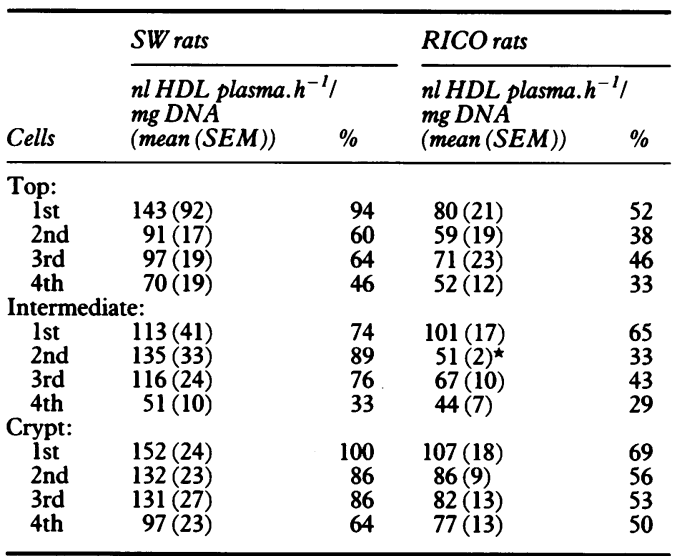

$\mathrm{n}=4$

The cells were collected after dividing the small intestine into four equal quarters (1st, 2nd, 3rd, 4th)

Crypt cells $=$ fractions $7-9$, Weiser's method. ${ }^{10}$

Intermediate cells $=$ fractions 4-6, Weiser's method.

Top cells $=$ fractions $1-3$, Weiser's method.

${ }^{\star} \mathrm{p} \leqslant 0.05 v \mathrm{SW}$ rats.

\section{Results}

The HDL clearance rates in the various intestinal cells (in nl HDL plasma. $\mathrm{h}^{-1} / \mathrm{mg}$ DNA) from the top, intermediary, or crypt cells in the four quarters of the small intestine in the SW and RICO rats are presented in Table I. Although results were not statistically significant (because of the limited number of animals and the wide variation in individual animals) certain trends were apparent. Rat HDL uptake increased slightly from the top to the crypt cells in the four quarters of the small intestine in both groups of animals (50-140 nl HDL. $\mathrm{h}^{-1}$ at the top, versus 80-150 nl HDL.h $\mathrm{h}^{-1}$ at the crypt). Consequently, the HDL uptake rate all along the small intestine was approximately 1.1 to 1.5 times higher in the crypt cells than in those of the upper villus in RICO or SW animals. Expressed per cell, the HDL clearance was slightly lower in RICO than in SW enterocytes, whatever their location in the small intestine or on the villus (Table I).

Cholesterol synthesis, also expressed per $\mathrm{mg}$ of cellular DNA (dpm/100 $\mu \mathrm{Ci}\left[{ }^{14} \mathrm{C}\right]$-acetate.mg DNA), was high in the first quarter (duodenum), low in the midgut (second and third quarters), and high in the terminal ileum (fourth quarter of the small intestine) of the SW rat (Table II). For the second, third, and fourth quarters, the rates of cholesterogenesis were generally approximately two or four times higher in the crypt cells compared with those of the upper villus. In RICO rats, in all intestinal segments, however, cholesterogenesis was higher in the crypt than in the upper villus cells. Except for the top cells of the first quarter and the intermediary cells of the fourth quarter, cholesterogenesis was always higher (two to four times) in the intestinal mucosa of RICO rats than SW rats.

The figure summarises the relationship between mean HDL uptake and cholesterol synthesis in mucosal cell fractions obtained from SW and RICO rats fed the semipurified laboratory chow. Expressed as a percentage of the value

TABLE II Sterol radioactivity $\left(\mathrm{dpm} / 100 \mu \mathrm{Ci}{ }^{14} \mathrm{C}\right.$ acetate. $m g$ DNA) in the enterocytes of SW and RICO rats killed 70 minutes after a subcutaneous injection of ${ }^{14} \mathrm{C}$ acetate. (Mean percentage value of cholesterol radioactivity in the duodenal crypt cells in SW rats)

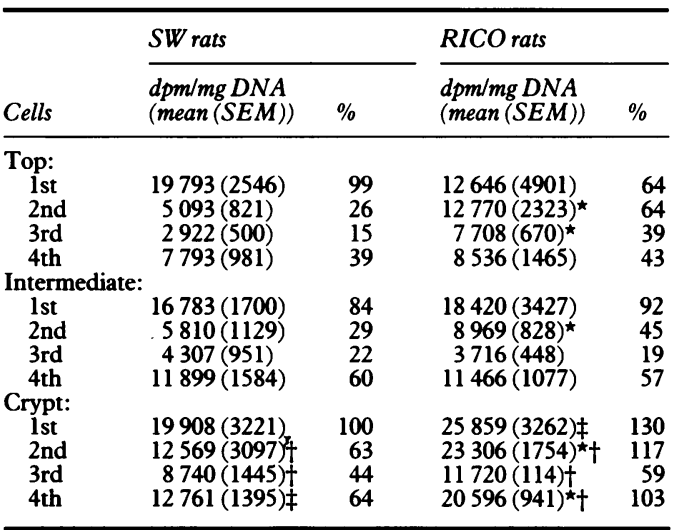

$n=4$

$\mathbf{n}=4$. equal quarters (1st, 2nd, 3rd, 4th).

Crypt cells = fractions 7-9, Weiser's method. ${ }^{10}$

Intermediate cells $=$ fractions 4-6, Weiser's method. Top cells $=$ fractions $1-3$, Weiser's method. $\star p \leqslant 0.05 v$ SW rats; $\nmid p<0.05 v$ top and intermediate cells; $\pm \mathrm{p}<0.05 v$ top cells. 
Relationship of high density lipoprotein $(r H D L)$ uptake and cholesterol synthesis in mucosal cell fractions obtained from normocholesterolaemic $S W$ $(\bullet$, no correlation) and genetically

hypercholesterolaemic hypercholesterolaemic
RICO rats $(0$, dotted line: $y=14 \cdot 8+1 \cdot 52 x ; p<0 \cdot 006)$ The data are expressed as a percentage of the value obtained for crypt duodenal cells in SW rats $(\%$ cholesterogenesis: see values Table II;\% HDL cholesterol uptake: values Table I were corrected from cholesterol HDL concentration).

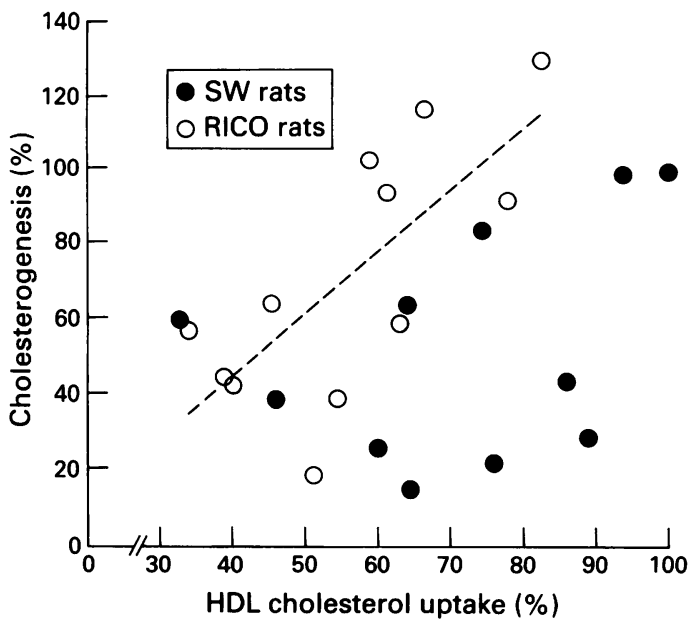

obtained for the duodenal crypt cells, no correlation was found between cholesterogenesis and HDL uptake in the enterocytes from SW rats, while a linear relationship was found $(p<0.006$, $y=14 \cdot 8+1 \cdot 52 x$ ) for the RICO rats, and there was no correlation between SW and RICO animals. The Spearman rank coefficient (rs), which is a non-parametric statistic, gives the same answer as regression analysis $(r s=0.377, p>0.05$ for $S W$ and RICO values, $n=24 ; r s=0.691, p=0.015$ for RICO values, $n=12$ ). It seems, however, that HDL uptake and cholesterogenesis varied in a similar fashion along the villus/crypt axis in both groups of animals. HDL uptake did not change for a crypt cell (or a top one) according to its location in the first, second, third, or fourth quarters of the small intestine, while cholesterol synthesis varied over a range of two to four. Moreover, the rate of intestinal cholesterol synthesis for the hypercholesterolaemic RICO rats was generally 1.5 to two times higher than that for the SW animals for a similar or even slightly lower HDL cellular uptake.

\section{Discussion}

Our experiments quantitate the in vivo rates of HDL uptake and sterol synthesis along the length of the small intestine, as well as along the villus/crypt axis. Firstly, the use of ${ }^{14} \mathrm{C}$ acetate for estimating in vivo cholesterol synthesis was analysed and validated. ${ }^{16}$ This method has been shown to give results similar to tritiated water for estimating cholesterol synthesis in the intestinal mucosa. ${ }^{3}$ Secondly, the use of the ${ }^{14} \mathrm{C}$ sucrose pulse method has also been discussed critically. ${ }^{18}$ We showed that experiments over too short a term (eight to 12 hours) give overestimated FCR values compared with 24 hour experiments.

The intestinal cell represents a very interesting model for examining the regulation of cholesterol balance throughout a differentiated tissue in vivo. ${ }^{341920}$ The duodenal and jejunal top cells are the main site of dietary and biliary cholesterol absorption, ${ }^{21}$ while the duodenal crypts and distal ileal cells are mainly responsible for cholesterol synthesis. ${ }^{3420}$ These cells are also important for the uptake and degradation of circulating $\mathrm{LDL}^{67}$ and $\mathrm{HDL} .{ }^{8}$ Stange and Dietschy showed that cholesterol synthesis and LDL uptake are regulated independently in the rat small intestinal mucosa. ${ }^{7}$ A similar question about HDL uptake and cholesterol synthesis arises. This study was undertaken to answer this question using in vivo techniques.

The mucosal intestinal cell cleared $50-140 \mathrm{nl}$ plasma HDL. $\mathrm{h}^{-1} / \mathrm{mg} \mathrm{DNA}$ (top cells) or $80-155$ nl HDL. $h^{-1} / \mathrm{mg}$ DNA (crypt cells) in the SW and RICO rats respectively - that is 10 to $20 \mathrm{ng}$ HDL protein. $\mathrm{h}^{-1} / 10^{6}$ cells (or $1 \mathrm{mg}$ cell protein); a value similar to the one obtained by Suzuki et al on isolated rat mucosal cells. ${ }^{8}$ The HDL clearance by the intestinal cell seemed to be five to 10 times less than that of liver cells $(0 \cdot 01-0 \cdot 02 \mu \mathrm{l}$ plasma HDL. $\mathrm{h}^{-1} / 10^{6}$ cells and $0 \cdot 1 \mu \mathrm{l}$ plasma HDL. $h^{-1} / 10^{6}$ cells respectively. ${ }^{12}$ Let us empasise that similar values for HDL3 internalisation can be calculated from the data from Stange's laboratory ${ }^{22}$ in cultured small intestinal crypt cells. Moreover, these authors observed that a minimal HDL3 degradation seemed to occur since the accumulation of degradation products reached only $5-10 \%$ of the amount bound to the cell.

In terms of cholesterol uptake, $0 \cdot 07-0 \cdot 15$ nmol HDL cholesterol enters the crypt cells while only $0.05-0.14 \mathrm{nmol}$ HDL cholesterol $. h^{-1} / \mathrm{mg}$ cell DNA enters the top cells, showing a decreasing gradient of cholesterol HDL input along the crypt/villus axis similar to that observed by Dietschy et al concerning LDL clearance. ${ }^{7}$ Dietschy's estimated LDL cholesterol clearance values reached $1.3 \mathrm{nmol}$ cholesterol.mg DNA/ $\mathrm{h}^{-1}$ in crypt cells and 0.5 nmol in the top ones - that is 10 times higher than the HDL cholesterol clearance found in this study and in that of Suzuki et al. ${ }^{8} \mathrm{We}$ can calculate from the data of Suzuki et al that the rLDL cholesterol uptake in the intestinal cells averages $0.2 \mathrm{nmol}$ cholesterol $/ \mathrm{mg}$ cell DNA that is three to seven times less than the values reported by Dietschy. ${ }^{7}$ Nevertheless, it is noteworthy that HDL uptake, LDL uptake, and cholesterogenesis decrease progressively during the short 'life' of the mucosal cell born in the crypt and sloughed to the top of the villus. This suggests a decreasing number of apo $\mathrm{B} / \mathrm{E}$ and apo AI receptors during the ageing of the enterocyte along the crypt/villus axis.

It is also noteworthy that, as for LDL clearance, ${ }^{7}$ rat HDL uptake is essentially unchanged in the top cells located all along the small intestine while sterol synthesis varies up to eightfold (Figure). Kagami et al who increased to fivefold the rate of sterol synthesis by cholestyramine, did not also observe any changes in the in vitro capacity of mucosal cells to bind, internalise, and degrade ${ }^{125} \mathrm{I}$-labelled HDL $3 .{ }^{23}$ In the crypt cells, where cholesterogenesis is generally much higher and varies up to fivefold, the HDL uptake rates (two times higher than those in the top cells) are essentially constant along the length of the small intestine in normocholesterolaemic as well as in genetically hypercholesterolaemic rats. Regulating factors other than HDL uptake must be proposed to explain the modulation of cholesterogenesis along the small intestine in normocholesterolemic rats and the higher cholesterol synthesis of the mucosal cells in genetically hypercholesterolaemic RICO animals. 
Taken together, these studies show that local cholesterol synthesis and the HDL uptake rate are independently regulated in the small intestine mucosal cells.

Studies were partly supported by a CRE grant awarded by INSERM (Caisse Régionale d'Assurance Maladie de l'Ile de France 89-91).

Mrs M Sauvage (IE INSERM) has given up her technical assistance in the middle of these studies. We are grateful to $\mathrm{Mr} \mathrm{M}$ Moqué who prepared the figures and Mrs L Boivin for her excellent secretarial assistance.

1 Chevallier C, Lutton C. The intestine is the major site of cholesterol synthesis in the rat. Nature New Biology 1973; 242: 61-2.

2 Lutton $\mathrm{C}$. The role of the digestive tract in cholesterol metabolism. Digestion 1976; 14: 342-56.

3 Perrodin M, Lutton C. In vivo cholesterol synthesis by the digestive tract in the rat. I. Topological study. Reprod Nutr Dev $1985 ; 25$ : 647-57.

4 Perrodin M, Sérougne C, Lutton C. In vivo cholesterol synthesis by the rat digestive tract. II. A study of turnover. Reprod Nutr Dev 1985; 25: 659-69.

5 Lutton C, Magot T, Chevallier F. Effect of dietary long chain fatty acids on the rates of turnover processus of cholesterol, on its origins and on its distribution in the intestinal lumen, in the rat. Reprod Nutr Dev 1980; 20 5A: 1467-79.

6 Spady DK, Bilheimer DW, Dietschy JM. Rates of receptordependent and receptor-independent LDL uptake in the hamster. Proc Natl Acad Sci USA 1983; 80: 3499-503.

7 Stange EF, Dietschy JM. Cholesterol synthesis and low density lipoprotein uptake are regulated independently in density lipoprotein uptake are regulated independently in rat small intestinal

8 Suzuki N, Fidge N, Nestel P, Yin J. Interaction of serum lipoproteins with the intestine. Evidence for specific high density lipoprotein-binding sites on isolated rat intestinal mucosal cells. F Lipid Res 1983; 24: 253-64.

9 Cardona-Sanclemente LE, Verneau C, Mathé D, Lutton C. Cholestérol metabolism in the genetically hypercholesterolemic rat (RICO). I. Measurement of turnover processes. Biochim Biophys Acta 1987; 919: 205-12.

10 Weiser MM. Intestinal epithelial cell surface membrane glycoprotein synthesis. An indication of cellular differentiation. F Biol Chem 1973; 248: 2536-41.

11 Sérougne C, Férézou J, Rukaj A. Effects of excess dietary L-cystine on the rat plasma lipoproteins. Ann Nutr Metab 1984; 28: 311-20.

12 Van Tol A, Dallinga-Thie GM, Van Gent T, Van't Hooft FM. Specific sarurable binding of rat HDL to rat kidney membranes. Biochem Biophys Acta 1986; 876: 340-51.

13 Pittman RC, Dattie AD, Carew TE, Steinberg D. Tissues sites of degradation of low density lipoprotein: application of a of degradation of low density lipoprotein: application of a method for determining the fate of
Natl Acad Sci USA 1979; 76: 5345-9.

14 Lutton C, Ouguerram K, Sauvage M, Magot T. Turnover of ${ }^{14} \mathrm{C}$-sucrose and uptake by organs in the normal or genetic-
, ${ }^{14} \mathrm{C}$-sucrose and uptake by organs in the normal or genetically hypercholesterolemic (RICO) rat using a cons

15 Day AJ, Wahlquist ML, Campbell DJ. Differential uptake of cholesterol and of different cholesterol esters by atherosclerotic intima in vivo and in vitro. Atherosclerosis 1970; 11: 301-20.

16 Lutton C, Férézou J, Sérougne C, Verneau C, Champarnaud $\mathrm{G}$, Magot $e t$ al. Critical analysis of the use of ${ }^{14} \mathrm{C}$-acetate for measuring in vivo rat cholesterol synthesis. Reprod Nutr Dev 1990; 30: 71-84.

17 Ferezou J, Sulpice JC, Lutton C. Evidence for different isotopic enrichment of acetyl-CoA used for cholesterol isotopic enrichment of acetyl-CoA used for cholesterol synthesis in liver and intestine: a study in the rat by mass fragmentography after intravenous infusion
Biochim Bophys Acta 1986; 875: 227-35.

18 Champarnaud G, Ouguerram K, Magot T, Lutton C. Overestimation of the lipoprotein catabolic clearance (FCR) measured in short duration experiments. F Pharmacobio Dyn 1992; 15: 541-6.

19 Sérougne C, Lutton C. Répartition du cholestérol d'origine plasmatique dans la villosité intestinale du Rat. $\mathcal{f}$ Physiol Paris 1982; 78: $170-4$.

20 Lutton C, Perrodin M, Cardona-Sanclemente LE, Sérougne C. In vivo cholesterol synthesis by the rat digestive tract III. Evaluation of modulating factors. Reprod Nutr Dev 1986; 26: Evaluation

21 Lutton C, Brot-Laroche E. Biliary cholesterol absorption in normal or L-thyroxin fed rat. Lipids 1979; 14: 441-6.

22 Rogler G, Herold G, Stange EF. HDL3-retroendocytosis in cultured small intestine crypt cells: a novel mechanism of cholesterol efflix. Biochim Biophys Acta 1991; 1095: 30-8. 23 Kagami A, Fidge NH, Nestel PJ. Specific binding of high in rat intestinal mucosa. $\mathcal{F}$ Lipid Res 1985; 26: 705-12. 